\title{
Reduced free carrier absorption loss in midinfrared double heterostructure diode lasers grown by liquid phase epitaxy
}

\author{
M. Yin, A. Krier, ${ }^{\text {a) }}$ R. Jones, and P. J. Carrington \\ Department of Physics, Lancaster University, Lancaster, LA1 4YB, United Kingdom
}

(Received 22 March 2007; accepted 14 August 2007; published online 4 September 2007)

\begin{abstract}
An improved InAsSb/InAsSbP double heterojunction ridge laser was designed and grown by liquid phase epitaxy. The cladding layer absorption loss was minimized by the introduction of two undoped quaternary layers on either side of the active region to form a five layer epitaxial structure. The inserted layers also helped alleviate interdiffusion of unwanted dopants into the active region and reduced current leakage in the device. The resulting diode lasers operate readily in pulsed mode near $3.5 \mu \mathrm{m}$ at elevated temperatures and with a threshold current density as low as $118 \mathrm{~A} \mathrm{~cm}^{-2}$ at $85 \mathrm{~K}$. Compared to the conventional three-layer double heterostructure laser, the modified structure with reduced optical loss increased the maximum lasing temperature by $95-210 \mathrm{~K}$. (C) 2007 American Institute of Physics. [DOI: 10.1063/1.2779246]
\end{abstract}

There is increasing interest in the development of midinfrared $(2-5 \mu \mathrm{m})$ diode laser sources for applications in molecular spectroscopy, optical gas sensors, and free space optical communications. To access room temperature operation within this technologically difficult spectral range, several different device designs are being developed, including unipolar quantum cascade lasers ${ }^{1}$ and interband cascade lasers (ICLs) based on "W" structures. ${ }^{2-4}$ However, although promising, these devices contain many ultrathin layers (there are 3000 interfaces in ICL structures) and the fluctuation in composition, uncertainties in material quality and heterojunction roughness, waveguide fabrication, etc., are difficult to control in manufacture. ${ }^{5,6}$ The cascade lasers also have higher operating voltages than those of conventional bipolar diode lasers. In this work we demonstrate midinfrared diode lasers with improved performance fabricated using a much simpler approach based on liquid phase epitaxy (LPE). We report specifically on a five-layer double heterojunction (DH) laser with reduced optical loss emitting at $3.45 \mu \mathrm{m}$ and operating up to $210 \mathrm{~K}$.

LPE is a near equilibrium growth technique which produces epitaxial layers of high crystalline perfection containing few point defects and impurities. The relatively high growth rate $(\sim 1 \mu \mathrm{m} / \mathrm{min})$ is useful for the production of the cladding layers or broad waveguide regions in a high power diode laser. In addition, LPE growth also has the potential for cost effective device manufacture. For conventional DH diode lasers, a maximum operating temperature of $150 \mathrm{~K}$ (with $6 \mathrm{~W}$ output at $78 \mathrm{~K}$ ) has been achieved. ${ }^{7,8}$ To obtain higher operating temperatures and lower threshold current, it is necessary to reduce the Auger coefficient and free carrier leakage. The crucial role of internal loss $\left(\alpha_{i}\right)$ in limiting both the differential quantum efficiency $\left(\eta_{d}\right)$ and maximum operating temperature has been realized. ${ }^{9,10}$ The doping induced absorption loss for InAs related alloys at wavelengths around $3.4 \mu \mathrm{m}$ can be as high as $200 \mathrm{~cm}^{-1}$. ${ }^{11}$ Therefore, it is also important to minimize the optical loss originating from the highly doped cladding layers. Our laser design is based on the InAs ${ }_{1-x} \mathrm{Sb}_{x} / \mathrm{InAs}_{1-x-y} \mathrm{Sb}_{x} \mathrm{P}_{y} \mathrm{DH}$ alloy system, from which wavelengths covering most of the midinfrared spectral range

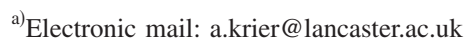

can be accessed through the adjustment of the alloy compositions. In the conventional DH laser structure, the $\mathrm{InAs}_{1-x} \mathrm{Sb}_{x}$ active region is sandwiched between two $\mathrm{InAs}_{1-x-y} \mathrm{Sb}_{x} \mathrm{P}_{\mathrm{y}}$ cladding layers. Some of the optical mode overlaps with the highly doped cladding layers, which introduces optical loss due to free carrier absorption, as shown in Fig. 1(a). In our structure, undoped $\operatorname{InAs}_{0.61} \mathrm{Sb}_{0.13} \mathrm{P}_{0.26}$ layers are inserted between the heavily doped $\operatorname{InAs}_{0.61} \mathrm{Sb}_{0.13} \mathrm{P}_{0.26}$ cladding layers on either side of the $\mathrm{InAs}_{0.96} \mathrm{Sb}_{0.04}$ active region, as shown in Fig. 1(b), in an attempt to reduce the optical mode overlap with the heavily doped layers. The undoped layers also block unwanted impurity diffusion into the laser active region and give improved carrier confinement.

The active region composition of $\operatorname{InAs}_{0.96} \mathrm{Sb}_{0.04}$ was selected to emit within the atmospheric transmission window at the wavelength of $3.7 \mu \mathrm{m}$ at room temperature. Figure 1 shows the calculated fundamental TE mode profiles for the conventional and five-layer $\mathrm{DH}$ structures, where the thicknesses of the $\operatorname{InAs}_{0.96} \mathrm{Sb}_{0.04}$ active region and $\mathrm{InAs}_{0.61} \mathrm{Sb}_{0.13} \mathrm{P}_{0.26}$ cladding layers were 0.8 and $2.0 \mu \mathrm{m}$, re-

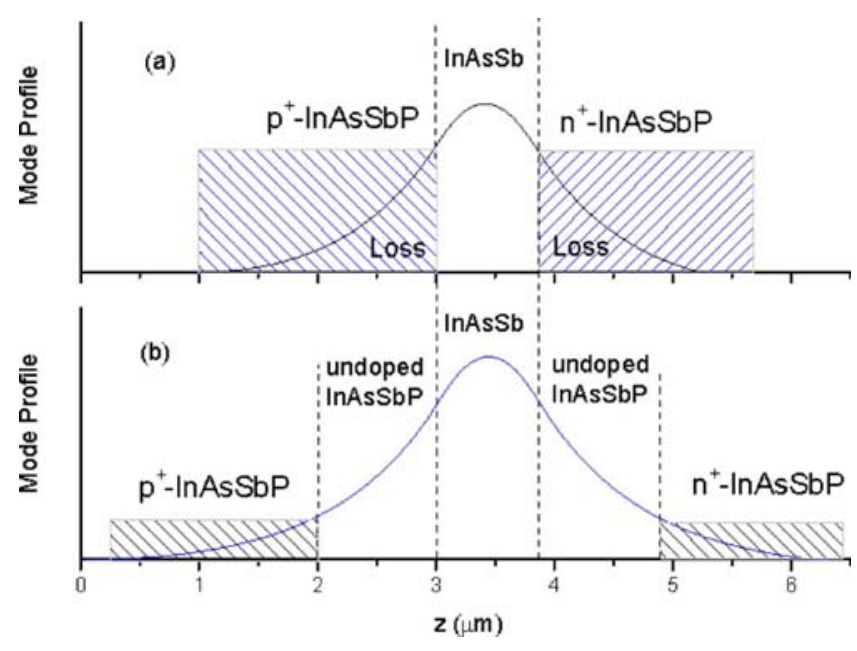

FIG. 1. (Color online) $\mathrm{InAs}_{0.61} \mathrm{Sb}_{0.13} \mathrm{P}_{0.26} / \mathrm{InAs}_{0.96} \mathrm{Sb}_{0.04}$ fundamental TE optical mode profile along the growth axis for (a) conventional three-layer $\mathrm{DH}$ laser and (b) five-layer $\mathrm{DH}$ structure with additional undoped $\mathrm{InAs}_{0.61} \mathrm{Sb}_{0.13} \mathrm{P}_{0.26}$ layers inserted between the InAsSb active region and the highly doped InAsSbP cladding layers. 

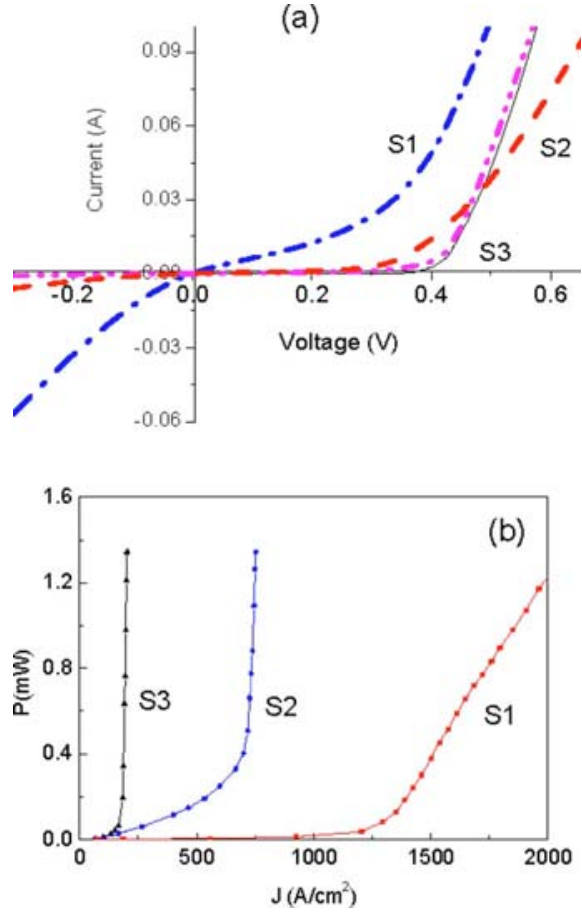

FIG. 2. (Color online) (a) Current-voltage and (b) light-current relationships for the three different samples at the temperature of $100 \mathrm{~K}$, where "thin" represents $2 \times 0.25 \mu \mathrm{m}$ inserted undoped epilayers (S2) and "thick" represents $2 \times 1 \mu \mathrm{m}$ inserted undoped epilayers (S3) in the device. $P$ is the output power measured from both facets.

spectively. The thickness of the undoped InAsSbP layers was selected to be (S1) $0 \mu \mathrm{m},(\mathrm{S} 2) 0.25 \mu \mathrm{m}$, and (S3) $1.0 \mu \mathrm{m}$ in the lasers which were subsequently fabricated. The fundamental transverse TE mode profile confinement factor $(\Gamma)$ was calculated as $35 \%$ for the conventional three-layer DH laser structure in Fig. 1(a). In this case $65 \%$ of the mode overlaps the highly doped cladding layers, which contributes significantly to the total optical loss in the device. In the five-layer DH structure of Fig. 1(b) the confinement factor is nearly the same $(32 \%)$ as that in the active region. However, the transverse mode overlap with the highly doped cladding layers is considerably decreased to $20 \%$, due to the insertion of the undoped layers.

The DH structures were grown onto (100) oriented $p$-type InAs substrates from indium-rich melts using a conventional multiwell graphite sliding boat and epitaxial growth technique which has been developed and described previously. ${ }^{12}$ The cladding layers were intentionally doped with Te ( $n$ type) up to a concentration of $5 \times 10^{18} \mathrm{~cm}^{-3}$ and with $\mathrm{Zn}$ ( $p$ type) up to $1 \times 10^{18} \mathrm{~cm}^{-3}$, respectively. The thickness of each epilayer was measured by scanning electron microscopy on cross-sections which were stained using the $A: B$ etch. The epilayer compositions were determined using both energy-dispersive $\mathrm{x}$-ray analysis and double crystal $\mathrm{x}$-ray diffraction measurements.

Edge emitting ridge laser structures were fabricated from the epitaxial wafers using conventional photolithography and wet chemical etching to produce ridges which were $0.5 \mu \mathrm{m}$ deep and $50 \mu \mathrm{m}$ wide. RF sputtering was used to deposit the $\mathrm{SiO}_{2}$ which was used as an insulating layer. Ohmic contacts were formed by thermal evaporation of $\mathrm{Au}: \mathrm{Zn}$ and $\mathrm{Au}$ :Te alloys at $150{ }^{\circ} \mathrm{C}$ on the $p$ and $n$ sides of the structures, respectively. Laser chips were mounted $n$-side (epilayer side)
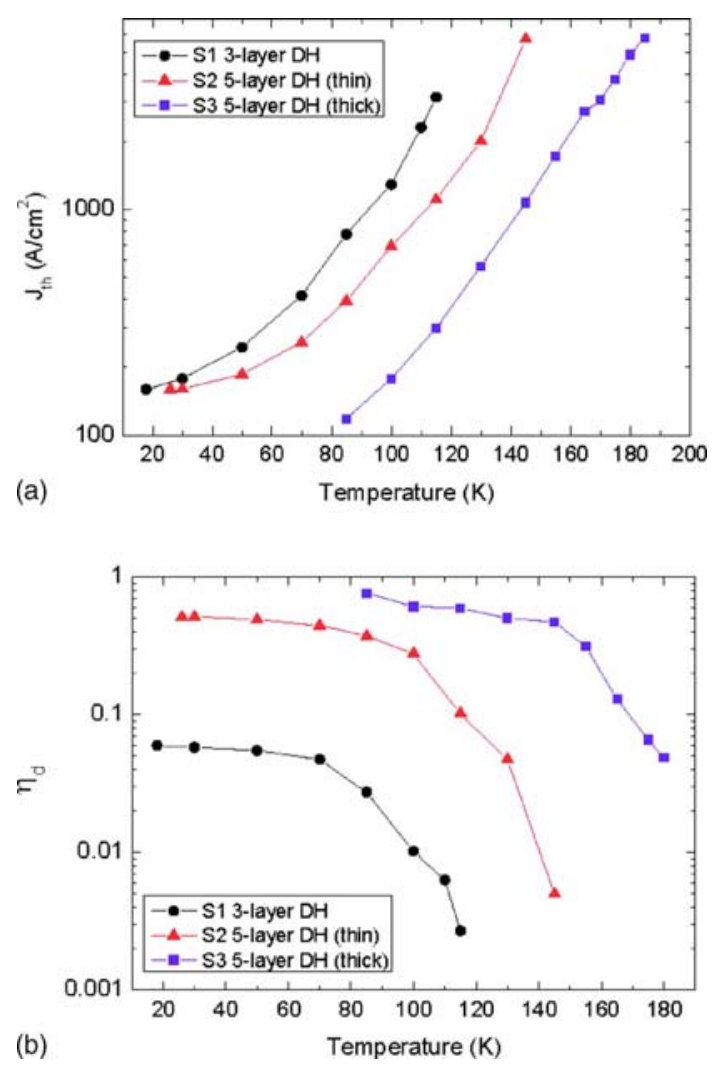

FIG. 3. (Color online) (a) Dependence of threshold current density $\left(J_{\text {th }}\right)$ on temperature $(T)$ and (b) the dependence of differential quantum efficiency on temperature for the samples S1, S2, and S3.

up onto TO-49 headers for testing. The spontaneous electroluminescence emission from sample S3 gave a peak at $3.70 \pm 0.02 \mu \mathrm{m}$ at room temperature. Current-voltage-light $(I-V-L)$ characteristics were measured at different temperatures for the different DH laser samples S1, S2, and S3 respectively. Figure 2 shows current-voltage $(I-V)$ and lightcurrent $(L-I)$ curves at $100 \mathrm{~K}$ for conventional three-layer and two different five-layer $\mathrm{DH}$ laser structures, each with a cavity length of $500 \mu \mathrm{m}$. The $L-I$ relationships were obtained under pulsed conditions using a pulse width of $100 \mathrm{~ns}$ and a frequency of $100 \mathrm{~Hz}$.

From the $I-V$ curves in Fig. 2(a), sample S3 $(1.0 \mu \mathrm{m}$ thick insertion layers) exhibits the least forward and reverse leakage current associated with improved confinement and reduced impurity inter-diffusion. The calculated $I-V$ curve is represented by the solid line and is in excellent agreement with the experimental data for S3. From Fig. 2(b), it is evident that the introduction of two thin layers (S2) reduces the threshold current density and increases the efficiency at the same operating temperature. Increasing the thickness of the undoped insertion layers produces further improvements as is evident from the curve for S3.

The experimental results in Fig. 3 show the temperature dependence of the different lasers. Sample S3 has the lowest threshold current density $\left(J_{\text {th }}=118 \mathrm{~A} \mathrm{~cm}^{-2}\right.$ at $\left.85 \mathrm{~K}\right)$, the highest laser differential quantum efficiency $\left(\eta_{d}=76 \%\right.$ at $85 \mathrm{~K})$, slowest efficiency degradation $(\sim 2.4$ times from 85 to $155 \mathrm{~K}$, compared to approximately ten times from 75 to $150 \mathrm{~K}$ in Ref. 7), and almost constant characteristic temperature $T_{0}$ over a wide temperature range $\left(T_{0}=24 \mathrm{~K}\right.$ from 85 to $185 \mathrm{~K}$ ), due to the insertion of the two $1 \mu \mathrm{m}$ AIP license or copyright; see http://apl.aip.org/apl/copyright.jsp 
TABLE I. Comparison of the five-layer DH laser (S3) with some midinfrared lasers of similar construction at wavelengths of $3.3-3.5 \mu \mathrm{m}$ at temperatures of $80-100 \mathrm{~K}$.

\begin{tabular}{ccccc}
\hline \hline & $\begin{array}{c}J_{\text {th }} \\
\left(\mathrm{A} \mathrm{cm}^{-2}\right)\end{array}$ & $\eta_{d}(\%)$ & $\begin{array}{c}\alpha_{i} \\
\left(\mathrm{~cm}^{-1}\right)\end{array}$ & $\eta_{i}$ \\
\hline $\begin{array}{c}\text { Present work } \\
\text { S3 (100 K) } \\
\text { Conventional DH } \\
(100 \mathrm{~K})^{\mathrm{a}}\end{array}$ & 177 & 61 & 12 & 0.93 \\
$\begin{array}{c}\text { Asymmetric DH }(80 \mathrm{~K})^{\mathrm{b}} \\
\text { Type-II QW }(90 \mathrm{~K})^{\mathrm{c}}\end{array}$ & 300 & 34 & 42 & \\
\hline \hline & 150 & 30 & 30 & 0.67 \\
\hline
\end{tabular}

${ }^{\mathrm{a}}$ Reference 12 .

${ }^{\mathrm{b}}$ Reference 8 .

${ }^{\mathrm{c}}$ Reference 10 .

undoped layers. The internal loss in our lasers (at $100 \mathrm{~K}$ ) was determined experimentally in the usual manner by measuring the differential efficiency of lasers with different cavity lengths. The loss in sample S1 was $\sim 60 \mathrm{~cm}^{-1}$ and is much higher than that of sample $\mathrm{S} 3$ which was reduced to $12 \mathrm{~cm}^{-1}$. As shown in Table I, our DH laser (S3) also has higher efficiency and lower loss compared to other similar midinfrared lasers of simple construction.

Some typical measured laser spectra at different temperatures are presented in Fig. 4 for sample S3, where a maximum laser emission wavelength of $3.45 \mu \mathrm{m}$ was obtained at $170 \mathrm{~K}$. The maximum temperature of laser opera-

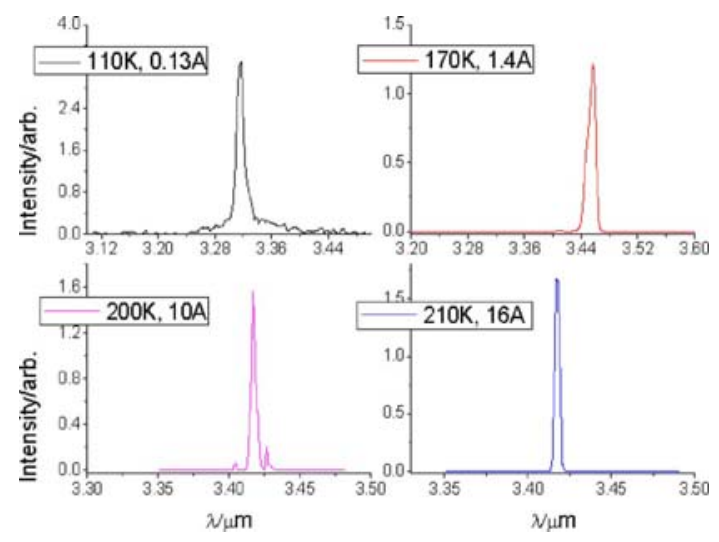

FIG. 4. (Color online) Typical laser spectra measured from S3 using different injection currents and temperatures. tion in pulsed mode was found to be $210 \mathrm{~K}$, which is more than $90 \mathrm{~K}$ higher than that of the conventional three-layer $\mathrm{DH}$ laser ( 1 1, maximum lasing temperature $\sim 115 \mathrm{~K}$ ) using the same growth and processing conditions.

In summary, an improved five-layer $\mathrm{DH}$ laser structure of relatively simple construction has been fabricated by LPE and characterized. As expected from simulations these midinfrared diode lasers exhibited reduced threshold current ( $118 \mathrm{~A} / \mathrm{cm}^{2}$ at $85 \mathrm{~K}$ ), superior efficiency degradation with increasing temperature and a significantly higher maximum operating temperature of $210 \mathrm{~K}$. We attributed this mainly to the addition of the undoped layers which reduced the optical loss to $12 \mathrm{~cm}^{-1}$. Using the same epi-layer growth and device processing conditions, laser operating temperature was increased by $90 \mathrm{~K}$ in the five-layer $\mathrm{DH}$ structure (S3), compared with the conventional three-layer DH structure (S1). The characteristic temperature $T_{0}=24 \mathrm{~K}$ for the five-layer $\mathrm{DH}$ laser remained constant over a wide temperature range from 85 to $185 \mathrm{~K}$.

The authors wish to thank HM Government Communications Centre for supporting this research.

${ }^{1}$ J. S. Yu, S. R. Darvish, A. Evans, J. Nguyen, S. Slivken, and M. Razeghi, Appl. Phys. Lett. 88, 041111 (2006).

${ }^{2}$ C. L. Canedy, W. W. Bewley, M. Kim, C. S. Kim, J. A. Nolde, D. C. Larrabee, J. R. Lindle, I. Vurgaftman, and J. R. Meyer, Appl. Phys. Lett. 90, 181120 (2007).

${ }^{3}$ C. L. Canedy, W. W. Bewley, J. R. Lindle, C. S. Kim, M. Kim, I. Vurgftman, and J. R. Meyer, J. Electron. Mater. 35, 453 (2006).

${ }^{4}$ W. W. Bewley, J. R. Lindle, and J. R. Meyer, Appl. Phys. Lett. 81, 1166 (2002).

${ }^{5}$ A. V. Gopal, H. Yoshida, T. Simoyama, N. Georgiev, T. Mozume, and H. Ishikawa, Appl. Phys. Lett. 80, 4696 (2002).

${ }^{6}$ R. Teissier, D. Barate, A. Vicet, C. Alibert, A. N. Baranov, X. Marcadet, C. Renard, M. Garcia, C. Sirtori, D. Revin, and J. Cockburn, Appl. Phys. Lett. 85, 167 (2004).

${ }^{7}$ M. Aydaraliev, N. V. Zotova, S. A. Karandashov, B. A. Matveev, M. A. Remennyi, N. M. Stus, and G. N. Talalakin, Appl. Phys. Lett. 81, 1166 (2002).

${ }^{8}$ D. Wu, B. Lane, H. Mohseni, J. Diaz, and M. Razeghi, Appl. Phys. Lett. 74, 1194 (1999).

${ }^{9}$ H. Q. Le, C. H. Lin, S. J. Murray, R. Q. Yang, and S. S. Pei, IEEE J. Quantum Electron. 34, 1016 (1998).

${ }^{10}$ A. Wilk, M. El Gazouli, M. El Skouri, P. Christol, P. Grech, A. N. Baranov, and A. Joullie, Appl. Phys. Lett. 77, 2298 (2000).

${ }^{11} \mathrm{http} / / / \mathrm{www}$.ioffe.rssi.ru/SVA/NSM/Semicond/InAs/

${ }^{12}$ A. Krier, H. H. Gao, and V. V. Sherstnev, J. Appl. Phys. 85, 8419 (1999). 